\title{
Contrast-enhanced 3D micro-CT of plant tissues using different impregnation techniques
}

\author{
Zi Wang $^{1}{ }^{0}$, Pieter Verboven ${ }^{1}$ and Bart Nicolai ${ }^{1,2^{*}}$
}

\begin{abstract}
Background: X-ray micro-CT has increasingly been used for 3D imaging of plant structures. At the micrometer resolution however, limitations in X-ray contrast often lead to datasets with poor qualitative and quantitative measures, especially within dense cell clusters of plant tissue specimens. The current study developed protocols for delivering a cesium based contrast enhancing solution to varying plant tissue specimens for the purpose of improving 3D tissue structure characterization within plant specimens, accompanied by new image processing workflows to extract the additional data generated by the contrast enhanced scans.

Results: Following passive delivery of a 10\% cesium iodide contrast solution, significant increases of 85.4 and $38.0 \%$ in analyzable cell volumes were observed in pear fruit hypanthium and tomato fruit outer mesocarp samples. A significant increase of $139.6 \%$ in the number of analyzable cells was observed in the pear fruit samples along the added ability to locate and isolate better brachysclereids and vasculature in the sample volume. Furthermore, contrast enhancement resulted in significant improvement in the definition of collenchyma and parenchyma in the petiolule of tomato leaflets, from which both qualitative and quantitative data can be extracted with respect to cell measures. However, contrast enhancement was not achieved in leaf vasculature and mesophyll tissue due to fundamental limitations. Active contrast delivery to apple fruit hypanthium samples did yield a small but insignificant increase in analyzable volume and cells, but data on vasculature can now be extracted better in correspondence to the pear hypanthium samples. Contrast delivery thus improved visualization and analysis the most in dense tissue types.

Conclusions: The cesium based contrast enhancing protocols and workflows can be utilized to obtain detailed 3D data on the internal microstructure of plant samples, and can be adapted to additional samples of interest with minimal effort. The resulting datasets can therefore be utilized for more accurate downstream studies that requires 3D data.
\end{abstract}

Keywords: Contrast agent, Porosity, Microstructure, Image analysis, Cesium iodide, Vasculature, Cell size, Tomato, Apple, Pear

\section{Background}

Composition and internal tissue structure dictates the physical and functional characteristics of plants [1]. Thus, anatomical parameters such as cell size, geometry, tissue composition and architecture must be known to understand the physiology of plants in detail [2-5]. Accurate three-dimensional (3D) anatomical data is necessary for modelling and understanding transport of water, nutrient

\footnotetext{
*Correspondence: bart.nicolai@kuleuven.be

${ }^{1}$ Division MeBioS, Department of Biosystems, KU Leuven - University

of Leuven, Willem de Croylaan 42, 3001 Leuven, Belgium

Full list of author information is available at the end of the article
}

and gases in plants. Thus, raw images in which the models are based on should be of high resolution, accuracy and throughput [6].

$\mathrm{X}$-ray micro computed tomography (X-ray micro-CT) has become popular for 3D plant tissue imaging [7-9]. Generational improvements to CT hardware and software has made the technique popular [10] with the scientific community since its initial introduction to medical imaging in 1972 [11]. Given that benchtop instruments have resolutions down to half a micrometer [12], contrast in water saturated specimens becomes a limiting factor in the determination of internal 3D microstructure instead 
of resolution. Thus, the ability to determine structural boundaries within dense clusters becomes exceptionally difficult [13]. Only with phase contrast imaging from synchrotron radiation, has micro-CT been able to somewhat overcome this problem, albeit at extreme expense [14, $15]$.

In principle, contrast of X-ray images is dependent on density, thickness and atomic composition of the sample [16]. Since biological samples are typically composed of low atomic weight elements, differential introduction of heavy elements into the sample can exponentially increase the attenuation of X-ray beams through the structures of interest. More specifically, the attenuation of the X-ray beam is approximately proportional to the cubic of the average atomic number [17]. Medical imaging currently exploits this concept through the use of contrast agents which have heavy elements embedded within [18].

Due to toxicity concerns, clinical contrast agents are based on barium sulfate or iodide compounds [19]. Which were also formulated with osmolality, iconicity and viscosity matching the requirements of human patients. As such, the use of medical contrast solution for plant specimens are limited as they were never designed to do so. Moreover, medical contrast agents are categorized as medical supplies, and are therefore restricted to radiology specialists. This further reduces its feasibility for use within the plant science domain.

To counter this limitation, a number of iodine and heavy metal compounds were explored for their viability for use within plant specimens [20]. However, results highlighted some significant shortcomings of these compounds along with their methodologies. For example, Lugol's solution causes significant tissue damage in the incubated samples, whereas phosphotungstic acid is prone to leeching from the sample and is toxic [21]. Bismuth tartrate requires extended incubation time and osmium tetroxide has poor penetrative properties while being extremely expensive and toxic [21]. Moreover, previously adapted protocols require extensive sample preparation including dehydration and fixation along with long incubation time with iodine contrast [22]. This automatically excludes plant specimens with high water content as viable samples.

So, the most ideal contrast agent for widespread usage should be readily accessible, non-toxic, inexpensive along with a simple and short incubation protocol. In theory, a solution with a heavy cation would suffice considering that the middle lamella that is present at the intercellular interface is rich in natively charged pectin [23]. Working from the heaviest to lightest metallic elements on the periodic table that have ionic compounds with these aforementioned properties. Cesium salts thus remain as one of the few metallic compounds that can potentially be used as a contrast enhancing agents. Considering that cesium salt variants comes with chloride, iodide and fluoride anions, care must be taken to choose the most compatible compound. However, the chloride and fluoride variants have relatively light anions, and they have the potential to be dehydrating and cytotoxic respectively. Therefore, cesium iodide emerges as a prime candidate as it in theory meets all the aforementioned requirements and both its cation and anion are composed of heavy elements. Moreover, it is reasonable to theorize that cesium cations will gravitate toward the charged pectin molecules providing contrast enhancement to cell boundaries. While the anion embedded solution should in theory diffuse through intercellular water and enhancing its contrast. However, the necessary concentration, incubation method and duration for successful utilization of the theorized contrast agent is unknown.

Thus, the potential benefits of utilizing cesium iodide as a contrast enhancing agent for X-ray micro-CT scans of plant tissues were experimentally tested. The contrast delivery protocols were optimized for use with commercially relevant fruit species, with an emphasis on minimal tissue damage to preserve scan accuracy. Additionally, plant specimens of varying intercellular air fractions were examined for use with the cesium iodide to determine usage feasibility as well as necessary specimen specific adjustments.

\section{Methods}

\section{Sample preparation and contrast incubation}

Hypanthium samples of "Kanzi" apples (Malus domestica cv. Kanzi) and "Conference" pears (Pyrus communis cv. Conference) harvested during the fall of 2015 were obtained from internal stock and purchased fresh from a local market respectively. The fruits were stored at $4{ }^{\circ} \mathrm{C}$ until used for experimentation (less than 7 days post acquisition). Hypanthium samples were extracted from the fruit via a cork borer with an inner diameter of $4.05 \mathrm{~mm}$, and the top $8 \mathrm{~mm}$ of the core sample was kept for experimentation and imaging.

Outer mesocarp samples were excised from greenhouse "Bonaparte" tomatoes (Solanum lycopersicum cv. Bonaparte) while petiolule and leaflet blade sections were obtained from the "Merlice" variety. Greenhouse tomatoes were picked prior to ripening at the first sign of color change, stored at room temperature and were used for experimentation within 1 day of picking. Mesocarp samples were excised by hand via a razor blade and samples approximately $4 \times 4 \times 7 \mathrm{~mm}$ were used for experimentation and imaging. Leaflet blade sections were obtained from leaves approximately $50 \mathrm{~mm}$ at the widest point in $5 \times 8 \mathrm{~mm}$ sheets with $300 \mu \mathrm{m}$ maximal thickness. 
Petiolule samples were cut in $10 \mathrm{~mm}$ long segments up to $50 \mathrm{~mm}$ from the leaflet blade, and imaged sections were approximately $2.5 \mathrm{~mm}$ in diameter.

In all experiments, plant samples were scanned with or without contrast treatment along with protective parafilm to prevent dehydration during imaging. All cesium iodide solutions (Acros Organics, Geel, Belgium) were prepared fresh prior to scan sessions. Final necessary concentration was experimentally derived using apple hypanthium samples.

Contrast delivery in fruit samples was done either passively via diffusion or actively via vacuum impregnation. The passive method applies the contrast solution by sample submersion at room temperature where the time frame for diffusive incubation was determined experimentally. If the sample can be successfully enhanced via the passive method, no additional methods were tested. In the event the passive method was insufficient, the active method was applied. In essence, the active method applies an extra pulsed vacuum profile similar to that utilized to impregnate leaf samples with trehalose [24, 25]. Principally, the experimentally derived pulsed vacuum profile replaces intercellular air with the contrast solution, thus making it easier for the contrast solution to fully diffuse throughout the sample.

Conversely, intact leaflet blade and petiolule samples were partially submerged to utilize the natural transpirational pull found in leaves and vasculature. Incubation time was optimized per sample type and experimentally determined with ambient conditions set at $22{ }^{\circ} \mathrm{C}$ and $30 \%$ $\mathrm{RH}$. Leaflet and petiolule sections were excised for scanning following contrast incubation.

\section{$\mathrm{X}$-ray micro-CT acquisition and reconstruction}

All scans were acquired via a Phoenix Nanotom microCT system (General Electric, Heidelberg, Germany). Projection images were captured per sample on a 12-bit $2304 \times 2304$ detector with voxel resolutions of $2.5-$ $3.0 \mu \mathrm{m}$ (sample type dependent). X-ray tube voltages of $45-75 \mathrm{kV}$ (sample dependent) were applied to capture 2400 projection images with an exposure time of $500 \mathrm{~ms}$ per projection, resulting in a $20 \mathrm{~min}$ scan time per sample. Octopus Reconstruction 8.9.2 (Inside Matters, Gent, Belgium) was used to for reconstruction utilizing a filtered back projection algorithm. Ring artifact and noise filters were applied to improve overall image quality. Reconstructed images were downscaled to 8 bits to reduce computational requirements during image processing.

\section{Image processing, segmentation and analysis}

Processing workflow was derived from previously published works [5]. However, as contrast enhanced scans yield substantially better definition, the workflow was modified to better harvest the additional data. Sub-volumes were extracted from the reconstructed 3D volume for analysis, and all sub-volumes utilized for analysis were greater than the minimum representative volume of $1.3 \mathrm{~mm}^{3}$ as previously determined in apple hypanthium samples [26]. Due to the inevitable damage to the outer edges of the scanned samples, volume of interests (VOIs) of $2400 \times 2400 \times 2400 \mu \mathrm{m}$ were utilized to analyze hypanthium samples. As tomato samples were even more delicate and damage prone, a reduced VOI of $2000 \times 2000 \times 2000 \mu \mathrm{m}$ was utilized for analysis. However, as leaflet and petiolule samples are highly two dimensional and anisotropic, it was not possible to define a 3D VOI. Thus, representative images from undamaged regions were used to demonstrate the effect of the contrast solution.

Image segmentation was necessary to convert greyscale data to binary to reduce computational load and was done via a histogram based multi-thresholding module in Avizo 9.2 (FEI, Bordeaux, France) with assistance from the Sobel operator (edge detection to determine the approximate cell boundaries). Despeckling and opening operations were performed to reduce noise in the binary images, and segmented cells in fruit tissue were subjected to watershed transform for further object separation. Incomplete objects in contact with the VOI border were removed and a debris filter based on equivalent cell diameter was instituted to remove nonsensical objects. Debris filters of 40 and $80 \mu \mathrm{m}$ were set for apple hypanthium and tomato mesocarp samples. However, due to the presence of brachysclereids [27], no lower filter was set for pear hypanthium samples. Regardless, all remaining objects were labelled and subjected to a more detailed $3 \mathrm{D}$ analysis for parameters, such as equivalent spherical diameter, sphericity, anisotropy, number of cells, analyzable cell volume (\%). The effective cell diameter, 3D shape, directionality, quantity and gains in analyzable data were subsequently assessed and compared to control samples. In all fruit samples, 4 VOIs were analyzed to yield quantitative data.

Conversely, as the petiolule is a heterogeneous sample, image segmentation was adjusted to target visible cell structures. The workflow was similar to that of the fruit samples with the exception of the borderkill command. Moreover, the cuticle layer and the epidermis were removed to better visualize the internal structure of the petiolule.

\section{Errors induced by contrast solution incubation}

To assess whether the contrast enhancement protocol altered the samples in any way, a pair of Kanzi apple scans were performed prior to and following contrast 
enhancement. The datasets were registered and volumetric analysis was done using Avizo. Pre-alignment of principal axes was performed to reduce compute time. Transformation parameters were set to rigid and aniso-scale, and the correlation metric was utilized for the image registration. A matching sub-volume of $1950 \times 1950 \times 1950 \mu \mathrm{m}$ was extracted from both datasets to determine changes to the sample prior to and after contrast enhancement. An exclusive or (XOR) function was utilized to highlight the difference between the images and highlighted voxels were subjected to quantitative analysis.

\section{Statistical analysis}

All quantitative comparisons between control and contrast treated samples were subjected to independent $t$ tests with a sample size of four per analysis group. Statistical analysis was performed utilizing Prism 6 (GraphPad Software, La Jolla, USA). For normalized figures, statistical analysis was performed on the raw data. In all instances, statistical significance was stated if the $p$ value was less than 0.05 .

\section{Results}

The working concentration of the cesium iodide solution was determined experimentally by embedding solutions of up to $10 \% \mathrm{w} / \mathrm{v}$ concentration in Kanzi hypanthium samples with a pulsed vacuum profile. $2.75 \mu \mathrm{m}$ voxel resolution scans were obtained to demonstrate the effect of the contrast agents on the pixel intensity of cell boundaries and contrast filled air spaces (Fig. 1). As the ability to properly define intercellular boundaries relies on the detectable intensity differences between the cell fraction (grey pixels) and the contrast agent (light grey to white pixels). When greyscales were binarized based on pixel intensity with assistance from a Sobel edge detection operator, it became obvious that solution concentrations under $5 \%$ resulted in incomplete edge detection (data not shown) than those returned by solutions over $5 \%$. The shortcoming is especially obvious at $1 \%$ cesium iodide concentration, where the noise floor is high and the boundaries were nearly undetectable. Therefore, it was unsurprising that the datasets were not useful for further processing. Working concentration of cesium iodide were set at $10 \%$ as a result of this experiment set.

\section{Optimization of contrast delivery protocols}

As handling of fragile fruit samples inevitably induces certain degree of damage, testing protocols were selected based upon the fragility of the sample. In order to minimize the risk of sample damage, contrast delivery was first done passively with $10 \%$ cesium iodide solution. Only in the event that passive delivery failed to yield sufficient results, was the more harsh active protocol utilized. In any case, both delivery protocols were explored and optimized per sample type as needed (Table 1). Conditions such as incubation time, vacuum pressure, pulse profile was determined via a combination of internal and published work $[24,25]$. The chosen protocols were selected based on the ability to detect or mark cell edges in the sample center and high density clusters, as well as the feasibility of image processing protocols from the datasets with experimental workflows in Avizo 9.2.

\section{Active delivery of contrast and potential detrimental effects of vacuum delivery}

Passive delivery was insufficient for apple hypanthium samples due to incomplete and inconsistent contrast solution migration. Thus, an adapted pulsed vacuum profile was utilized to deliver the contrast solution throughout the sample. Although the modified vacuum protocol was successful, the derived dataset must be assessed for damage or distortion due to the harshness of the protocol itself. To accomplish this, a cylindrical sample of apple hypanthium was scanned prior to and following contrast incubation with the vacuum impregnation protocol. The resulting images stacks were registered and resamples to common spatial coordinates, and a central VOI was cropped out for processing. Binary images of the cells (white) and air spaces (black) from scans pre and post contrast enhancement are shown in Fig. 2a, b. While differences between the two volumes (white, Fig. 2c) exist, the differences between even with the inclusion of vasculature and partially flooded airspaces was $7.8 \%$. However, it was determine that air spaces and vasculature occupies $1.7 \%$ of the VOI, as they are now distinguishable from the remainder of the structures. The real difference between cells in terms of volume is approximately $6.1 \%$.

\section{Passive delivery of contrast via diffusion}

Trials with pear hypanthium samples were done in 30 min incubation intervals for the passive protocol. Contrast was insufficient at $30 \mathrm{~min}$ of incubation due to the lack of definition towards the sample center. Extending the incubation time to $60 \mathrm{~min}$ resulted in sufficient edge detection in the center of the sample, and extension to $90 \mathrm{~min}$ yielded little improvement. Similarly, tomato outer mesocarp samples were tested in $30 \mathrm{~min}$ initially. However, sample damage and/or destruction was evident at the 30 min mark. Reducing the incubation time to 20 min still yielded significant sample damage. Thus, the intervals were shortened to $5 \mathrm{~min}$ and retested up to the 15 min mark. At the 10 min mark, definition was sufficient in the sample center in which edge detection was possible. While extension of the incubation time to 15 min yielded no discernable improvements in boundary 

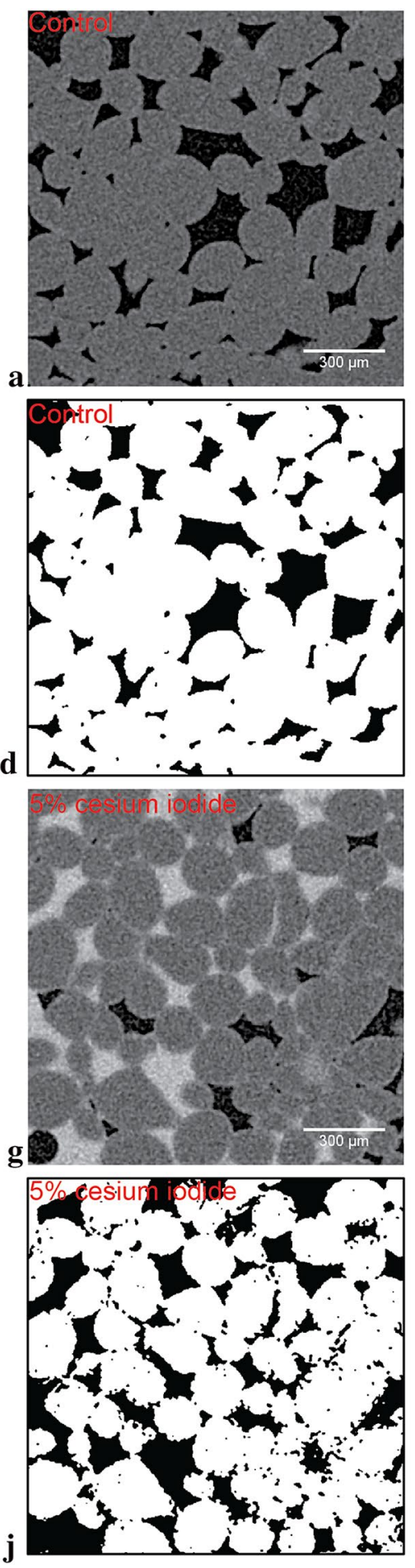
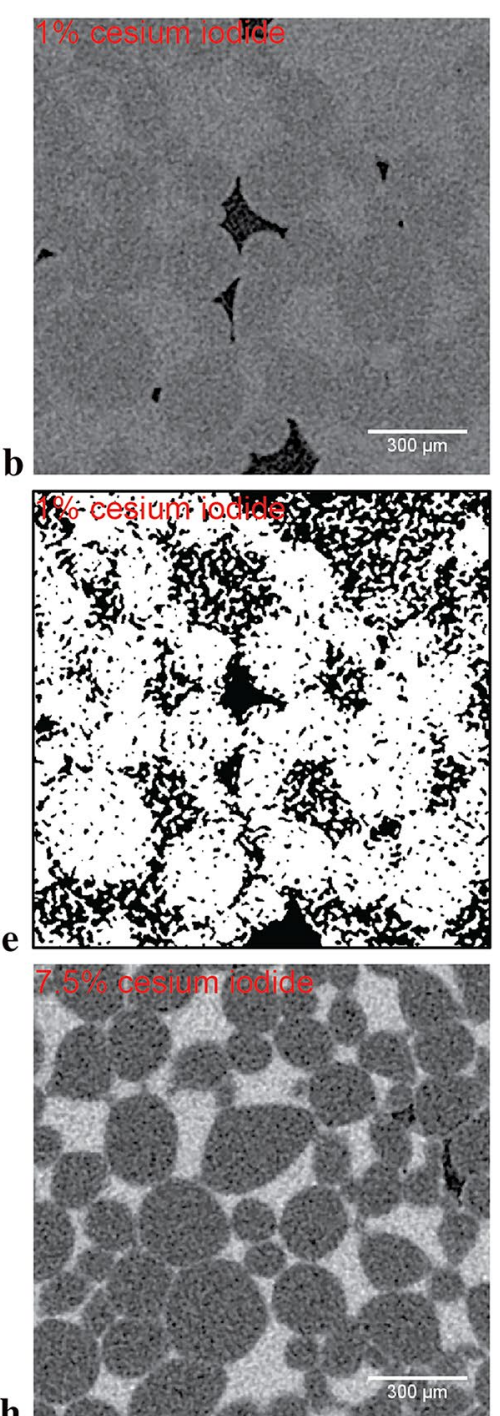

h

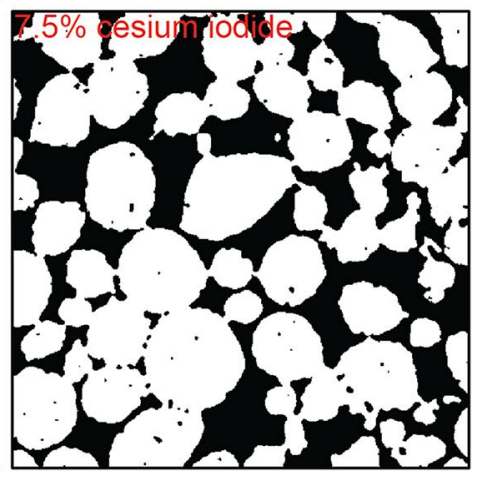

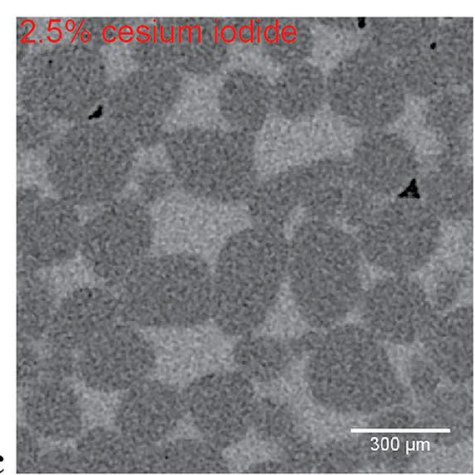
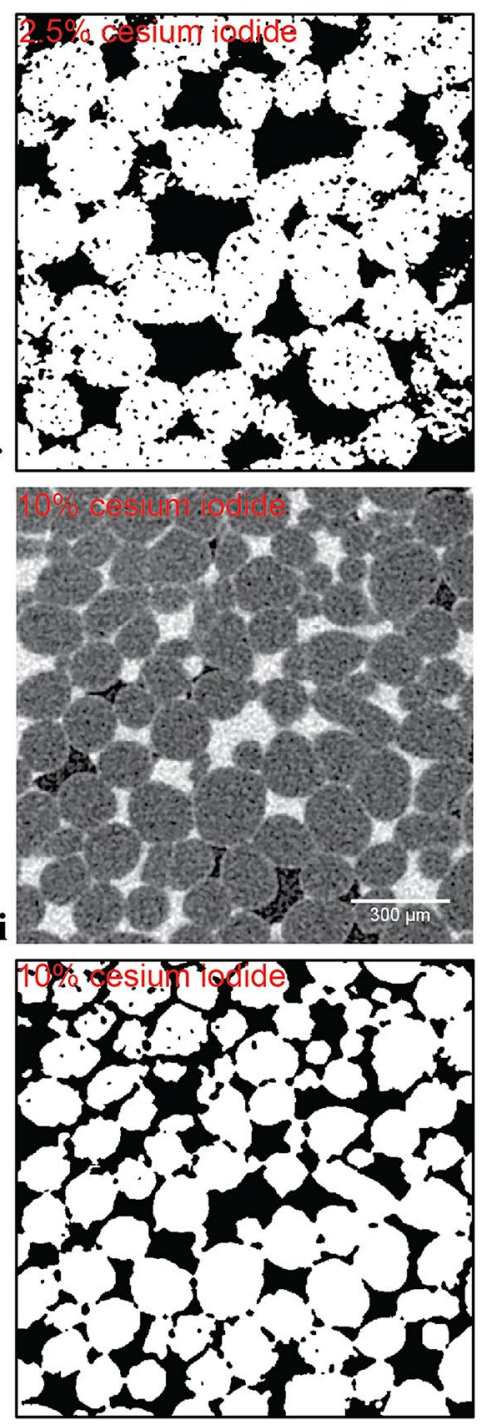

Fig. 1 Contrast altering effects of varying concentrations of cesium iodide delivered to apple (cv. Kanzi) hypanthium. Greyscales (a-c, $\mathbf{g}-\mathbf{i})$ and segmented binary images $(\mathbf{d}-\mathbf{f}, \mathbf{j}-\mathbf{I})$ are sequentially of control, 1, 2.5, 5, 7.5 and 10\% w/v cesium iodide embedded samples. In the control greyscale (a), intercellular air space and cells are designated by the black and dark grey pixels, respectively. Contrast embedded samples $(\mathbf{b}, \mathbf{c}, \mathbf{g}-\mathbf{i})$ have dark grey pixels designated as cells, while airspace can be either black or light grey pixels (where brightness of the grey is proportional to concentration of the solution). Thin light grey lines in between cells observed in $\mathbf{g}, \mathbf{h}$ and $\mathbf{i}$ marks cell boundaries. Semi-automatic segmentation was applied to the greyscale images to yield the matching binaries (below greyscale), which attempted to assign white pixels to the cells and black pixels to the background. All scale bars present are set at $300 \mu \mathrm{m}$ 
Table 1 Summary of experimental protocols used for contrast delivery

\begin{tabular}{|c|c|c|c|c|c|c|}
\hline \multirow[t]{2}{*}{ Samples } & \multicolumn{2}{|c|}{ Incubation timeframe } & \multicolumn{4}{|c|}{ Quick summary } \\
\hline & Duration & Successful? $^{\mathrm{a}}$ & \multicolumn{3}{|c|}{ Remarks } & $\begin{array}{l}\text { Active delivery } \\
\text { necessary? }\end{array}$ \\
\hline \multicolumn{7}{|l|}{ Passive delivery } \\
\hline Apple hypanthium & $30,60,90 \mathrm{~min}$ & - & \multicolumn{3}{|c|}{$\begin{array}{l}\text { Inconsistent and incomplete contrast penetration to center of sample, some } \\
\text { edges detectable but fragmented }\end{array}$} & + \\
\hline Pear hypanthium & $30,60,90 \mathrm{~min}$ & + & \multicolumn{3}{|c|}{$\begin{array}{l}\text { Consistent and sufficient contrast throughout sample, with detectable intercel- } \\
\text { lular boundaries }\end{array}$} & - \\
\hline Tomato mesocarp & $30,60 \mathrm{~min}$ & - & \multicolumn{3}{|c|}{ Sample damage and destruction notable, incubation time/interval too long } & - \\
\hline Tomato mesocarp & $5,10,15 \mathrm{~min}$ & + & \multicolumn{3}{|c|}{$\begin{array}{l}\text { Consistent and sufficient contrast throughout sample, detectable intercellular } \\
\text { boundaries. Sample damage starts to be observable at } 15 \mathrm{~min}\end{array}$} & - \\
\hline Tomato petiolule & $30,60,90 \mathrm{~min}$ & + & \multicolumn{3}{|c|}{$\begin{array}{l}\text { Consistent and sufficient contrast throughout sample, detectable cell edges in } \\
\text { parenchyma and collenchyma }\end{array}$} & - \\
\hline Tomato leaflet & $1,2,3,4,5 \mathrm{~h}$ & - & \multicolumn{3}{|c|}{ No detectable separation between mesophyll cells } & + \\
\hline Tomato leaflet & $10 \mathrm{~h}$ & - & \multicolumn{3}{|c|}{ Sample oversaturated with contrast solution } & + \\
\hline \multirow[t]{2}{*}{ Samples } & \multicolumn{4}{|c|}{ Vacuum profile } & \multirow{2}{*}{\multicolumn{2}{|c|}{$\begin{array}{l}\text { Results } \\
\text { Remarks }\end{array}$}} \\
\hline & Duration $+\mathrm{pr}$ & ressure & & Successful? & & \\
\hline \multicolumn{7}{|l|}{ Active delivery } \\
\hline Apple hypanthium & \multicolumn{3}{|c|}{$\begin{array}{l}\text { [3 min @ } @ 20 \text { kPa, } 10 \text { min @ ambient }] \\
\text { X2 }\end{array}$} & - & \multicolumn{2}{|c|}{$\begin{array}{l}\text { Incomplete penetration to center of samples, edges detection inconsistent } \\
\text { in cell clusters }\end{array}$} \\
\hline Apple hypanthium & \multicolumn{3}{|c|}{$\begin{array}{l}\text { [5 min @ } 20 \text { kPa, } 15 \text { min @ ambient }] \\
\text { X3 }\end{array}$} & + & \multicolumn{2}{|c|}{$\begin{array}{l}\text { Consistent contrast movement through sample with easily detectable } \\
\text { edges }\end{array}$} \\
\hline Leaflet & \multicolumn{3}{|c|}{$\begin{array}{l}{[3 \min @ 20 \mathrm{kPa}, 10 \mathrm{~min} @ \text { ambient }]} \\
\quad \mathrm{2} 2\end{array}$} & - & \multicolumn{2}{|c|}{$\begin{array}{l}\text { Sample destabilized, movement artifacts frequent and severe. Large sec- } \\
\text { tions of leaflet flooded with contrast with no detectable intercellular } \\
\text { boundaries }\end{array}$} \\
\hline
\end{tabular}

a Trials were considered successful if the contrast agent were distributed evenly and consistently throughout experimental sample and intercellular boundaries in cell clusters were detectable via a Sobel operator
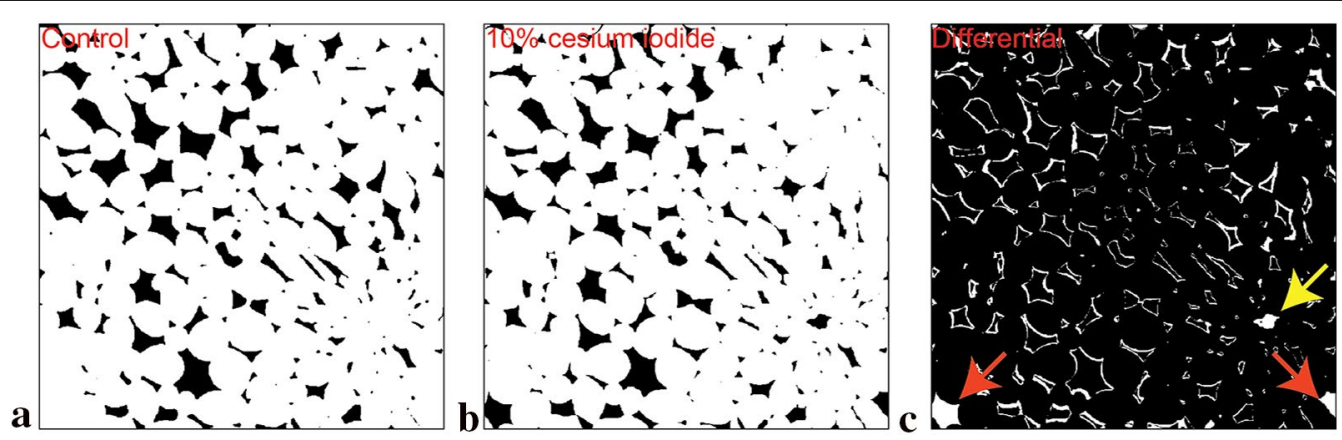

Fig. 2 Comparison of segmented binary images from matching control (a) and contrast enhanced (b) scans of apple (cv. Kanzi) hypanthium tissue. White pixels and black pixels represent cells and intercellular air spaces in $(\mathbf{a}, \mathbf{b})$. c Depicts the result of a XOR logical operation, where matching pixels of the two datasets from $\mathbf{a}$ and $\mathbf{b}$ are represented by black pixels, while mismatches are represented by white pixels. Red arrows highlights fluid filled intercellular spaces (caused by sample excision and manipulation), as the contrast solution can diffuse into the extracellular fluid (thus differentiating cellular and non-cellular materials). The yellow arrow highlights contrast embedded vasculature (ref to Fig. 3i for 3D representation)

definition, while damage within the sample increased notably. Therefore, passive contrast delivery for pear and tomato samples are set at 60 and 10 min respectively.

Unlike pear and tomato samples, leaf and petiolule samples were incubated with the superstructure intact.
Natural transpirational pull was exploited to enhance contrast delivery to the non-homogenous samples. Petiolule samples were excised from the leaf in $30 \mathrm{~min}$ incubation intervals. Core conductive vessels was visible at $30 \mathrm{~min}$, while intercellular boundaries remained largely 
unobservable. Extension of the incubation to $60 \mathrm{~min}$ resulted satisfactory results, while increase to $90 \mathrm{~min}$ resulted in negligible gain in contrast. Leaf blade sections unfortunately yielded unsatisfactory results in all tested intervals and protocols. Initial testing indicated that 30 min intervals was largely insufficient for leaf blade sections, as was the case for $1 \mathrm{~h}$ intervals up to $5 \mathrm{~h}$. Even at $5 \mathrm{~h}$, barely detectable changes in the veins were observed in the tomographs, and no discernable increases in contrast was noted. Leaving the sample overnight for $10 \mathrm{~h}$ resulted in a highly dehydrated sample with distorted dimension where leaf thickness was less than $50 \%$ of the control. Attempts were made with excised leaf blade sections incubated with a vacuum protocol. However, sample stability was insufficient for a high quality scan (internal testing data, not shown). Patches of contrast flooded cells along with movement artifacts provided no notable gain in contrast. Thus concluding the use of the cesium solution to enhance contrast in leaf samples.

\section{Analysis of contrast enhanced fruit tissue images}

Representative images of apple hypanthium scans prior to and following contrast enhancement are shown in Fig. 3a, b. The registered, binarized, watershed transform separated and labelled cells are shown in 3D (Fig. 3c-h) after removal of incomplete objects in 3D. Moreover, as contrast enhancement allowed vasculature segmentation, 3D plots demonstrate the connectivity and localization of the structure (Fig. 3i). Qualitatively, the dataset demonstrates a notable contrast improvement at cellular boundaries, where segmentation resulted in a notable reduction of large and irregular cell clusters in the corresponding 3D renderings. Quantitatively (Table 2), filtering was applied to labelled objects within the VOI to exclude debris, as well as unreasonably large cells/ clusters as well as geometrically unlikely cells (with lower and upper equivalent spherical diameter of 40 and $200 \mu \mathrm{m}$, and sphericity index of greater than 0.75 remain). Recovery of lost cell volume was done by label dilation to the reference provided by the Sobel operator to compensate for the imperfect initial segmentation. Even then, the contrast enhanced scans only yielded a $17.5 \%$ increase in analyzable volume, along with $0.5 \%$ of the sample volume belonging to the vasculature. However, contrast enhancement increased the number of analyzable objects from $951.3 \pm 88.9$ to $1312.8 \pm 140.3$, while mean equivalent spherical diameter increased insignificantly from $186.3 \pm 5.5$ versus $195.8 \pm 2.1 \mu \mathrm{m}$. Overall improvement due to contrast enhancement in apple hypanthium samples is quantitatively insignificant. Although we were able to increase the analyzable cell volume and cell count, there was an insignificant change in mean cell size.
Pear hypanthium samples enhanced with cesium iodide yields significant changes in results both qualitatively and quantitatively. However, the delicate nature of pear samples made it infeasible to scan the sample both prior to and following contrast delivery due to handling damage. Regardless, the contrast enhanced tomographs along with the binarized and 3D rendered volume demonstrates a notable improvement in the quality of the datasets compared to the control datasets (Fig. 4). Most notably, the presence of large objects with equivalent spherical diameters of over $500 \mu \mathrm{m}$ and sharp geometries have diminished (Fig. 4c, e, g). Moreover, brachysclereids (stone cells) with their dense radial cluster of parenchymal cells surrounding them can be segmented with contrast enhancement. The combined average of these stone cells are $1.1 \%$ of the overall cell volume, and varies depending on the VOI chosen. Quantitative analysis of pear hypanthium, however, demonstrates the degree of improvement of the contrast enhancement protocol (Table 2). First, the volume of cells with reasonable size and geometries after filtering (equivalent spherical diameter of under $200 \mu \mathrm{m}$, sphericity index above 0.75 ) rose by $85.4 \%$ along with a significant increase in cell count to $2540.3 \pm 12.9$ from $1060.3 \pm 15.5$ of control samples. Unsurprisingly, $139.6 \%$ increase in cell count along with a smaller $85.4 \%$ increase the volume of cells resulted in a reduction in cell sizes to $158.2 \pm 0.9$ versus $192.6 \pm 0.2 \mu \mathrm{m}$ found in the control datasets. Lastly, the average anisotropy of the cells in the enhanced scans is significantly higher compared to that of conventional scans at 0.70 versus 0.64 respectively.

Similar to pear hypanthium samples, tomato mesocarp tissue is extremely delicate and thus renders scans prior to and following contrast enhancement infeasible. Regardless, resulting tomographs along with binarized and $3 \mathrm{D}$ renderings demonstrates the effect of contrast enhancement (Fig. 5) both qualitatively and quantitatively (Table 2). Control images (Fig. 5a, c) demonstrates the shortcomings of conventional scans where no detectable cell boundaries are present in the tomographs. Furthermore, sharp angles can be observed on the rendered cell surfaces (Fig. 5e, g). Conversely, contrast enhancement yields clear cell boundary information (Fig. 5b, d), as well as significantly smoother cell surfaces in $3 \mathrm{D}$ renderings (Fig. 5f, h). The application of a $100 \mu \mathrm{m}$ debris filter and a sphereicity index cutoff of 0.75 , resulted in a significant increase of $38.0 \%$ was observed in the volume of reasonably sized and shaped cells within the VOI. However, neither cell count nor cell diameter changed significantly. The cell count increased slightly from $114.3 \pm 24.7$ to $162.3 \pm 23.3$, while cell volume decreased from $348.8 \pm 19.4$ to $331.4 \pm 18.8 \mu \mathrm{m}$ in control and contrast enhanced scans respectively. Thus, contrast 

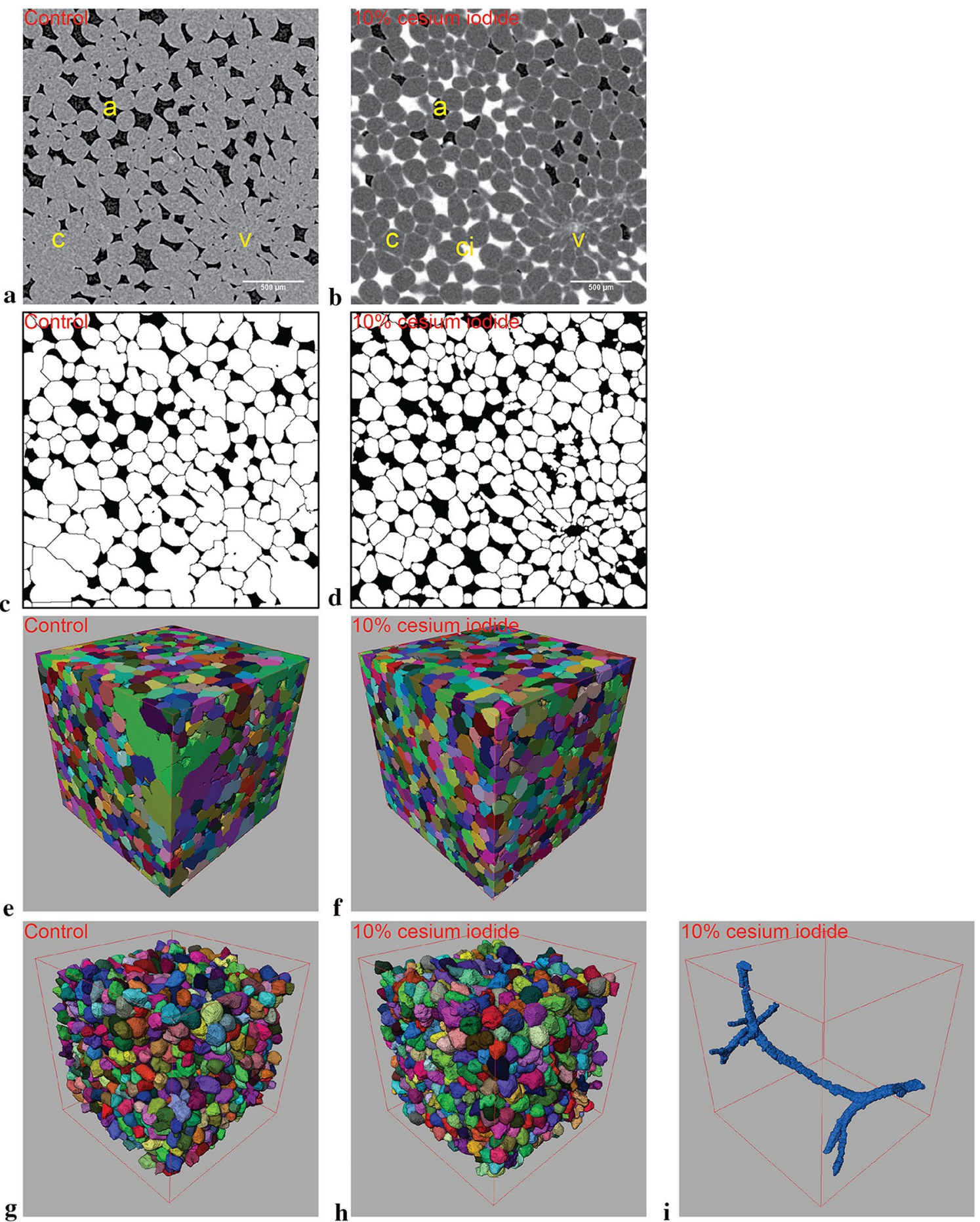

Fig. 3 Registered comparison between conventional and contrast enhanced scans of apple (cv. Kanzi) hypanthium (left and central columns respectively). Greyscale images of the conventional scan a contains air spaces "a" in black pixels, as well cells "c" and vasculature "v" in grey pixels. Contrast enhanced greyscale image b is composed of air space "a", cells "c", vasculature "v" as well as contrast solution "ci", which is represented by black, grey, light grey and white pixels respectively. Note that the contrast solution occupies not only intercellular spaces (marked by light grey lines), but a majority of the intercellular spaces were also invaded by the solution (such as the airspace marked by "ci"). $\mathbf{c}$, $\mathbf{d}$ Depicts segmented cells in white. $\mathbf{e}, \mathbf{f}$ Depict the segmented cell volumes in 3D with arbitrary colors, where individual cells in the same neighborhood are marked with a different color. $\mathbf{g}, \mathbf{h}$ Remove debris and incomplete cells that intersected the VOI boundaries in the respective control and contrast enhanced datasets. i Demonstrates the 3D localization of the vasculature bundle found within the scanned sample. All scale bars present are $500 \mu \mathrm{m}$ while all bounding edges are $2400 \mu \mathrm{m}$ 
Table 2 Summary of quantitative analysis of VOls after border kill, filtering by equivalent diameter and sphericity, \% volume of vasculature and/or brachysclereids, as well as percent increases in both retained cell volume and count

\begin{tabular}{|c|c|c|c|c|c|c|c|c|c|c|}
\hline \multirow[t]{2}{*}{ Samples } & \multicolumn{2}{|c|}{$\begin{array}{l}\text { Border killed cell } \\
\text { volume }\end{array}$} & \multicolumn{3}{|c|}{ Filtered cell volume } & \multicolumn{2}{|c|}{$\begin{array}{l}\text { Vasculature + brachy- } \\
\text { sclereids volume }\end{array}$} & \multicolumn{3}{|c|}{ Cell count } \\
\hline & Volume $\%$ & SEM & Volume\% & SEM & $\%$ increase & Volume\% & SEM & Number & SEM & $\%$ increase \\
\hline \multicolumn{11}{|l|}{ Kanzi $(n=4)$} \\
\hline Control & 65.13 & 1.12 & 23.23 & 2.28 & - & - & - & 951.25 & 88.95 & - \\
\hline Enhanced & 72.57 & 0.60 & 26.79 & 3.05 & 17.51 & 0.52 & 0.17 & 1312.75 & 140.35 & 38.00 \\
\hline \multicolumn{11}{|c|}{ Conference $(n=4)$} \\
\hline Control & 60.96 & 0.64 & 21.88 & 0.54 & - & - & - & 1060.25 & 15.47 & - \\
\hline Enhanced & 74.14 & 0.29 & 39.46 & 1.11 & $85.44^{*}$ & 1.11 & 0.05 & 2540.25 & 12.86 & $139.59^{*}$ \\
\hline \multicolumn{11}{|c|}{ Boneparte $(n=4)$} \\
\hline Control & 42.06 & 1.86 & 35.72 & 1.74 & - & - & - & 114.25 & 18.19 & - \\
\hline Enhanced & 49.63 & 1.93 & 45.74 & 3.64 & $37.98^{*}$ & 3.55 & 0.84 & 162.25 & 23.26 & 42.01 \\
\hline
\end{tabular}

Statistical significance denoted by * where $p<0.05$

enhancement within tomato mesocarp samples is limited to qualitative gains along with notable gains in the volume of cells after filtering.

\section{Contrast enhancement of petiolule and leaflet sample images}

Standard tomographic scans of leaf petiolule (leaf stems) only yields data on the size and localization of air pockets, epidermal tissue and mineral crystal deposits. Cells of the epidermal layer, collenchyma and parenchyma can neither be quantified nor localized, and no data was available on the location of the vasculature (Fig. 6a, b). Attempts to segment the greyscale images resulted in biologically irrelevant divisions in terms of the number of distinct objects, object size as well as shape. Conversely, contrast enhanced scans yielded cross sectional and longitudinal slices (Fig. 6c, d) with the epidermis, collenchyma, parenchyma and endodermis that are clearly distinguishable from each other. However, the qualitative improvements were still limited to the inner cell clusters. The method did not succeed in providing intercellular separation for the epidermis, nor was there sufficient resolution to properly isolate the vascular bundles (Fig. 6e). Regardless, after discarding unresolved structures, the inner cell clusters of the collenchyma and parenchyma can be segmented with relative ease to yield $3 \mathrm{D}$ data. Thus quantitative geometric parameters such as length, width, volume, surface area, sphericity are now available for further analysis in addition to the qualitative improvements.

Conversely, leaflet datasets experienced neither qualitative nor quantitative improvements even with contrast delivery. This is simply due to the fact that the contrast solution provided virtually no improvements to structural separation in any of the tested leaflet samples.
While split sections (parallel to leaf surface) of the leaves show the spatial distribution of the mesophyll cells along with the vasculature (Fig. 7), segmentation of individual cells were largely fruitless. Comparing no contrast with 5 and $10 \mathrm{~h}$ contrast embedded samples (Fig. $7 \mathrm{a}-\mathrm{c}$ respectively), only vasculature can be somewhat apparent after $5 \mathrm{~h}$ of contrast delivery (Fig. 7b). Even then, segmentation proved to be immensely difficult even with Sobel edge detection, and was abandoned due to impracticality. Furthermore, the contrast solution diminishes the ability to isolate and analyze mineral crystal deposits overtime. Thus reducing the level of quantitative analysis that can be done on the dataset. Similarly, cross sectional images corroborates such observations (data not shown due to redundancy). Where epidermal cells could not be differentiated from mesophyll cells, and palisade and spongy mesophyll cells cannot be separated from each other.

\section{Discussion}

Porous plant specimens can be easily examined with $\mathrm{X}$-ray micro $\mathrm{CT}$ with minimal effort, as there exists a thousand fold difference in the attenuation of air and soft tissue. In the ideal scenario, no sample preparation is necessary and the resulting data is of good accuracy like those previously reported [5]. However, substantial image processing can lose up to $74 \%$ of the cell volumes within the VOI depending on the fruit variety of interest [5]. Moreover, given that plant tissue is often not so porous, the power of porosity based image processing rapidly diminishes, and cell clusters have no discernible contrast. Thus, the current study aimed to overcome the limitations frequently faced by micro CT scanners by means of intercellular separation via a cesium iodide solution with minimal sample preparation. Definition improvements to 

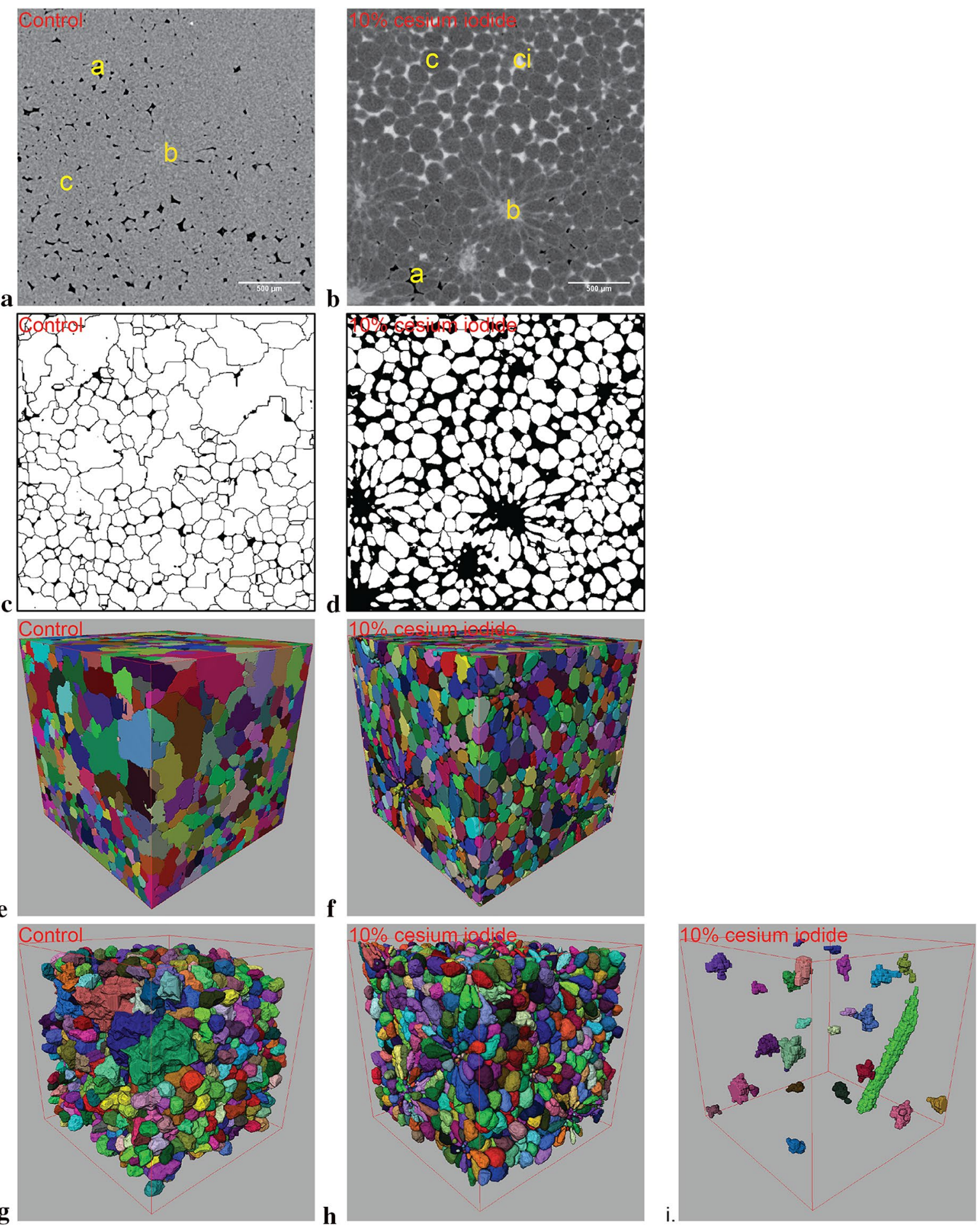

Fig. 4 Non-registered comparison between conventional and contrast enhanced scans of pear (cv. Conference) hypanthium (left and central columns respectively). Greyscale image of the conventional scan a contain air spaces in black pixels, as well as cells and brachysclereids in grey pixels labelled by "a", "c" and "b" respectively in the image. Greyscale image of contrast enhanced scan $\mathbf{b}$ contain black pixels marking air spaces "a", dark grey pixels marking cells "c", light grey pixels in clusters marking brachysclereids "b", near white pixels marking contrast flooded air spaces "ci", as well as light grey pixels in lines marking intercellular boundaries. c, d Depict the segmented cells in white. e, $\mathbf{f} T$ The segmented cell volumes in 3D with arbitrary colors, where individual cells in the same neighborhood are marked with a different color. $\mathbf{g}, \mathbf{h}$ Removes incomplete cells that intersected the VOI boundaries in the respective control and contrast enhanced datasets. $\mathbf{i}$ The approximate size and localization of the brachysclereids along with a vascular bundle (elongated green structure) in the VOI. All scale bars present are $500 \mu \mathrm{m}$ while all bounding edges are $2400 \mu \mathrm{m}$ 

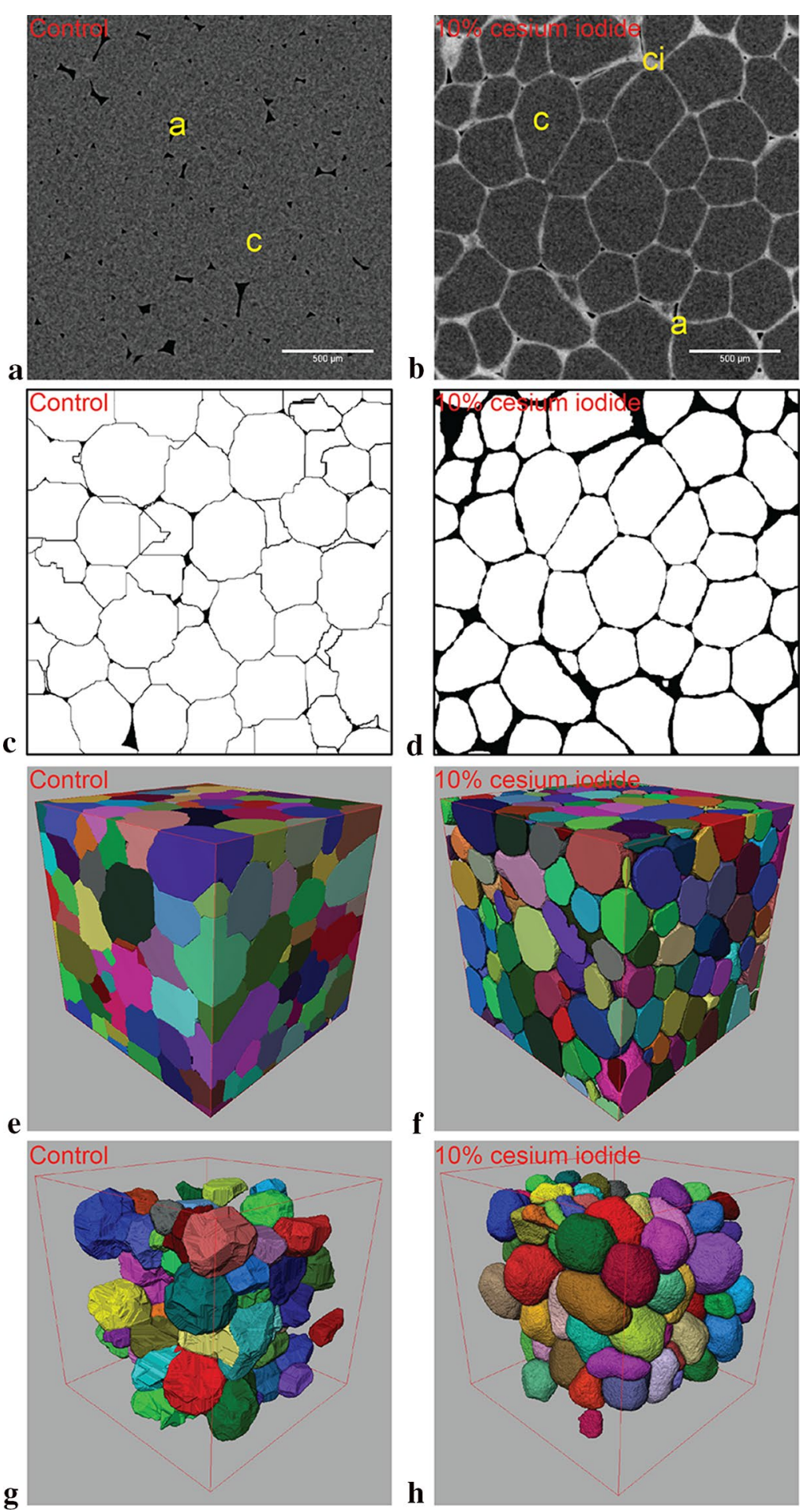

Fig. 5 Non-registered comparison between conventional and contrast enhanced scans of tomato (cv. Bonaparte) mesocarp (left and right columns respectively). Greyscale image of the conventional scan a contains air "a" labelled by black pixels, while cells "c" are labelled by dark grey pixels. Greyscale images of the contrast enhanced scan $\mathbf{b}$ contains air "a" labelled by black pixels, cells "c" labelled by dark grey pixels as well as contrast fluid "ci" labelled by near white pixels in intercellular airspaces and boundaries. $\mathbf{c}$, $\mathbf{d}$ The segmented cells in white. $\mathbf{e}$, $\mathbf{f}$ Depicts the segmented cell volumes in 3D with arbitrary colors assigned, where separate cells in the same neighborhood are marked with a different color. $\mathbf{g}$, h Removes debris and incomplete cells that intersected the VOI boundaries in respective control and contrast enhanced datasets. All scale bars are set at $500 \mu \mathrm{m}$ while all bounding edges are $2000 \mu \mathrm{m}$ 

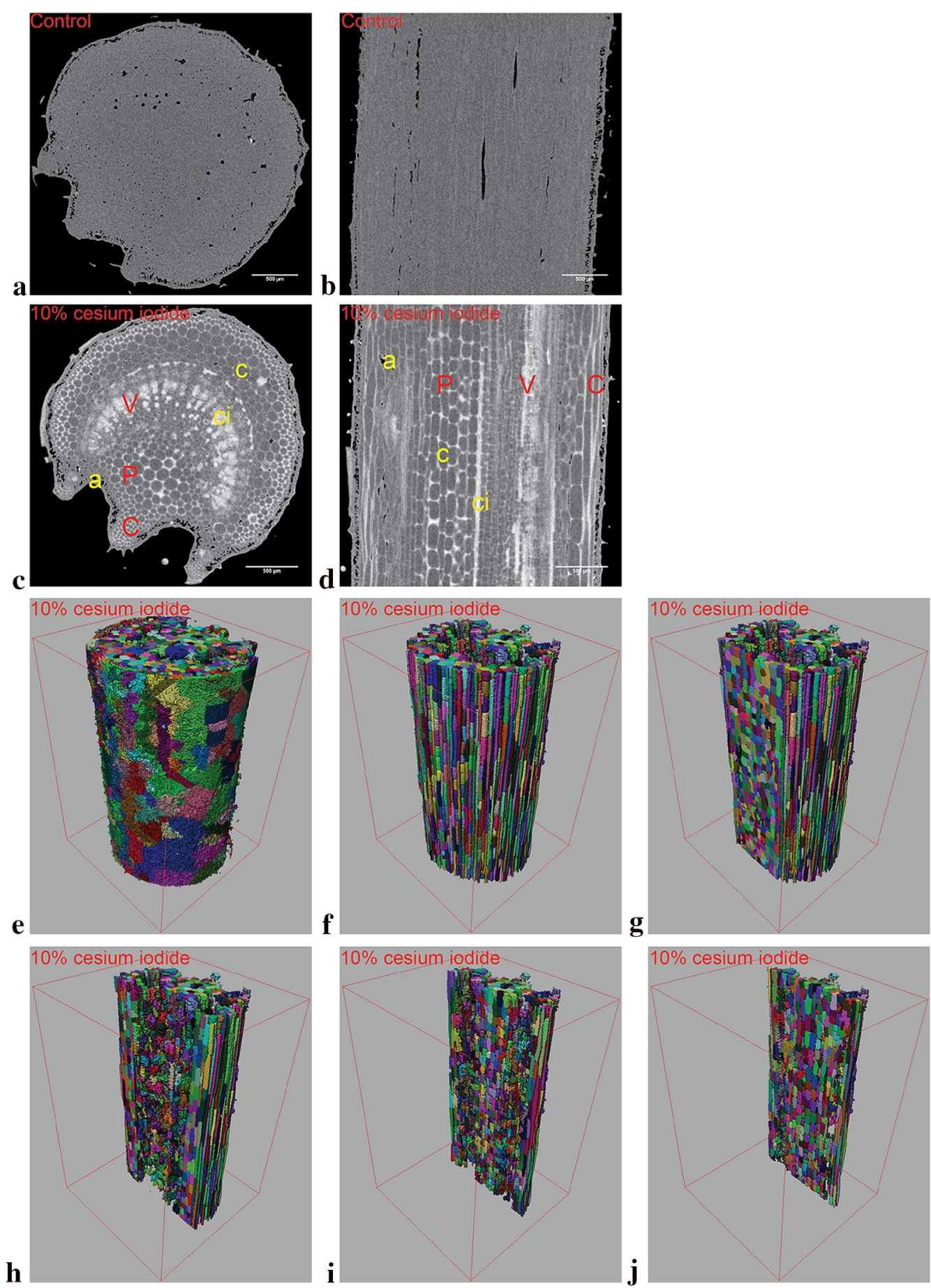

Fig. $\mathbf{6}$ Cross and longitudinal sections of tomato (cv. Merlice) leaf petiolule ( $\mathbf{a}, \mathbf{c}$ and $\mathbf{b}, \mathbf{d}$ respectively) from conventional and contrast enhanced scans (a, b and $\mathbf{c}$, d respectively). Sections from conventional scans $(\mathbf{a}, \mathbf{b})$ contain air spaces marked by black pixels, while grey pixels marks plant tissue. Sections from contrast enhanced scans (c, d) contain air spaces "a" in black pixels, cellular materials "c" in dark grey pixels as well as contrast solution "ci" in light grey pixels. Internal structures such as the vasculature " $\mathrm{V}$ ", parenchyma "P" and collenchyma " $\mathrm{C}$ " cell layers are distinctively visible. The enhanced greyscale images were segmented (not shown) and rendered in 3D with the vasculature removed but dermal layers left intact (e). Removal of the dermal layers resulted in the ability to view the individual cells of the parenchyma and collenchyma (f), where separate cells in the same neighborhood are marked with a different color. The rendered volumes were clipped at 750, 1250, 1750 and $2000 \mu \mathrm{m}$ ( $\mathbf{g}-\mathbf{j}$ ) from the bounding box edge to demonstrate the variance at different sample depths. All scale bars are set at $500 \mu \mathrm{m}$ while the bounding box is $3000 \times 3000 \times 4500 \mu \mathrm{m}$ in size 

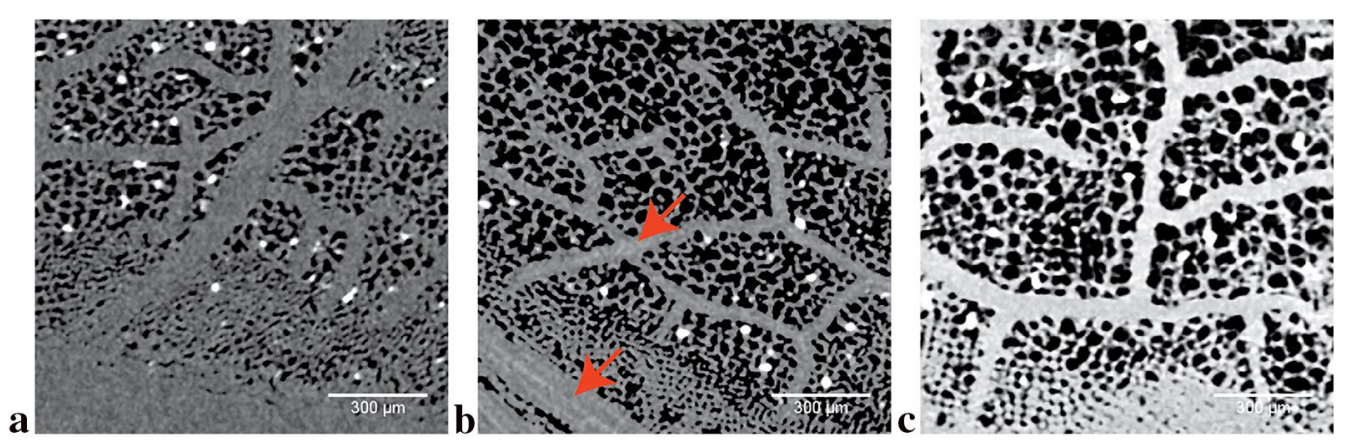

Fig. 7 Split section greyscale images of tomato leaflet with no contrast enhancement (a), $5 \mathrm{~h}(\mathbf{b})$ and $10 \mathrm{~h}$ (c) of contrast incubation by transpirational pull. In the unenhanced greyscale (a), leaf tissue is denoted by dark grey pixels, while air and crystalline deposits are marked by black and white pixels respectively. After $5 \mathrm{~h}$ of contrast incubation (b) faint traces of the contrast solution (light grey lines, see red arrows) are visible in the vasculature of the leaf (marked by grey pixels). After $10 \mathrm{~h}$ of incubation (c), the contrast solution invaded the plant tissue and oversaturation of the sample occurs. Leaf tissue is now replaced by light grey pixels, and no improvements to intercellular boundaries was observed over the conventional scans. All scale bars are set at $500 \mu \mathrm{m}$

the tomographs would in effect, improve the overall quality of subsequent downstream studies.

\section{Cesium iodide delivery is relatively simple and flexible}

High reproducibility is necessary to ensure the quality of the data generated by new protocols, simpler protocols are thus better to minimize the error rate. As demonstrated by the experimental results thus far, the contrast enhancement protocol itself does not contain inherently difficult steps. Moreover, tissues of varying porosities at 20, 10 and 5\%, being Kanzi apples, Conference pears and Bonaparte tomatoes were respectively tested [27-29] alongside tomato leaf petiolule to demonstrate protocol versatility. Even with increasing fragility of the samples going from apples to tomatoes, the cookie cutter approach to contrast enhancement requires only two optimization steps. The first being the duration of the contrast incubation, while the second being the necessity of vacuum impregnation techniques. Furthermore, the resulting detail of larger structures such as vasculature is comparable to previous studies [13], and the degree of detail on a cellular level is markedly better than those at similar resolutions [21]. This is especially notable considering the typical contrast incubation period is under an hour. While the incubation time is quite comparable with lower resolution studies on vasculature [13], it is however in stark contrast to previous high resolution studies where the incubation time was measured in days if not weeks $[21,22]$. This combined with the minimal sample preparation further reduces overall experimental time as well as distortions caused by sample preparation steps such dehydration and fixation. Similarly, the short incubation time in conjunction with powerful image processing workflows has the added benefit of preventing significant sample shrinkage and damage found in classical soft tissue contrast studies [30, 31]. That said, the sample preparation and mounting steps used in this study requires a high degree of care by the researcher. Firmly wrapping the samples with parafilm as gently and precisely as possible requires both steady hands and patience. If done correctly, reproducibility is not affected and compressive physical sample distortion can be minimized or eliminated. The subsequent difference in sample volumes should be around (or less than) $6.1 \%$ as observed in our study. Which is substantially better than that of the typical iodine based contrast protocols that induces up to $70 \%$ sample shrinkage in soft tissue [30]. Nevertheless, the contrast protocols utilized by this study are demonstrated to be simplistic and flexible, and can be used as a rough starting template for sample specific optimizations.

\section{Image segmentation of cesium iodide enhanced scans is still complex, but more realistic}

The ability to segment images based on pixel intensity rapidly diminishes when homogeneity of the material increases. Thus, watershed separation, while powerful [32], loses its effect when moving away from highly porous materials such as apples. Unsurprisingly, cell clusters with poor contrast presents itself as a significant challenge to image segmentation. Where resulting 3D data from standard watershed workflows contain angular outer geometries, unrealistic sizes and clustering. Thus, manual segmentation must be used if possible, at a cost of increased time consumption and lower replicability.

The cesium iodide overcomes the limitation faced by standard image processing protocols by increasing the 
pixel intensity of intercellular spaces, thus effectively marking cell boundaries. Ideally, the enhanced contrast would allow simple intensity based segmentation. However, the size of intercellular boundaries being much less than 5 microns (which is effectively up to two pixels wide in this study) places severe constraints on such simplistic workflows. Although image processing workflows cannot be simplified from those previously used [5], the accuracy of the datasets is notably improved. As an example, consider the pear hypanthium data presented. Instead of having a low volume of unrealistic cells along with large aggregate clusters, contrast enhanced image processing yields data on actual cellular boundaries. Quantity and localization of stone cells and vasculature is an added bonus from the workflow and adds to the value of such processing methods. Additionally, components such as cells, brachysclereids and vasculature all have distinctive characteristics with varying anisotropy, length, diameter, surface area and volume. Combination of these parameters can be utilized to extract interesting 3D data such as size and directionality of parenchymal cells surrounding brachysclereids, the brachysclereids themselves as well as vascular connectivity. Obviously, this is impossible to obtain without the contrast enhancement regardless of image processing workflow. All of which is a testament to the value of the enhancement properties of the contrast protocol.

However, it must be mentioned that care must be taken when processing enhanced datasets, as cell volume recovery is sometimes necessary since the contrast solution has a tendency to mark cell boundaries slightly thicker. Regardless, the segmentation and image processing workflow have been internally validated against a manual segmentation workflow as described in a previous publication [5]. Both automated and manually segmented data did not differ significantly (internal testing, data not shown), which is unsurprising since the process is only semi-automatic and manual input is required to ensure data integrity.

\section{Cesium iodide contrast enhancement is more successful with denser or heterogeneous tissue types}

As previously eluded to, segmentation difficulty of reconstructed images is roughly inversely proportional to the porosity of the sample. The porosity of apples can be greater than $20 \%$ [28], thus watershed assisted segmentation is reasonably accurate. Unsurprisingly, the degree of improvement provided by the contrast agent is only a $17.5 \%$ increase in cell volume that can be analyzed. Moreover, the minor changes to cell count and diameter puts them in line with previous reported figures [5]. While contrast enhancement is limited to qualitative gains for highly aerated samples, vascular mapping is now possible with the new protocols.

Conversely, tomatoes and pears have respective porosities of under 5 and $10 \%[27,29]$. This is complicated by the large cell count and cell volume of pear and tomato samples [5, 33], which challenges the feasibility and accuracy of existing segmentation techniques. Thus, the reliance on resource heavy methods such as microscopy [34, 35] and synchrotron based scanners $[5,27]$ is perfectly understandable. This study demonstrates that these expenses can be largely circumvented by applying the contrast protocol. In pear samples, both cell count and total cell volume that can be segmented increases significantly from contrast enhancement. Moreover, stone cells, surrounding parenchyma cells, and vasculature can be resolved from the reconstructed images, thus providing valuable information that is previously not obtainable. This makes the enhancement protocol highly worthwhile for use with similar samples as both qualitative and quantitative gains are obvious. For tomato samples, the gains were more qualitative than quantitative. Consider Fig. $5 \mathrm{~g}$, where cell boundaries are highly angular which deviates from previous 2D and 3D imaging work [36, 37]. The feasibility of utilizing these segmented images for downstream studies is limited. Conversely, contrast enhancement yields more plausible surface geometries along with an increase retained cell volume after filtering. This significantly increases the plausibility of utilizing such datasets for downstream studies. Unsurprisingly, highly variable cell sizes in the outer mesocarp [36] limited the quantitative significance of the increases in cell count. Nevertheless, contrast enhanced scans can provide more reasonable 3D data in terms of cell size, shape, orientation when compared to microscopy data. Even advanced methods such optical granulometry $[37,38]$ has severe limitations, and is bound by microtome section thickness, sample preparation time, and destruction of 3D characteristics. These limitations are particularly problematic as mesocarp cells often exceed thickness of microtome slices.

Similarly, leaflet petiolule and conductive macrostructures are low in porosity fractions [39, 40], as their primary function is structural support and fluid transport. The lack of intercellular air spaces meant that segmented images (data not shown) yielded data that are completely unusable for any downstream studies. Contrast enhancement yields 3D data on size, shape, orientation, quantity of collenchyma and parenchyma cells in the petiolule (data not shown) along with vasculature localization. Admittedly, the data on the dermal layers are not useful (Fig. 6e), and vasculature information is minimal due to limited definition. Sufficient quantitative data on the parenchyma and collenchyma were obtained to isolate them. The resulting $3 \mathrm{D}$ renderings demonstrates the 
quantity, orientation and cell diameters with comparable detail compared to similar microscopy studies [41, 42].

\section{Cesium iodide contrast is subject to limitations}

Although contrast enhancement is obvious for most samples examined in this study, the agent itself is not applicable for all sample types.

First, cellular separation by contrast enhancement of highly two dimensional samples such as leaves [43] was not achieved. Thus contrast enhanced scans yielded no discernable improvements over conventional micro CT scans [44]. This is unsurprisingly as the passive relies on transpiration pull to draw the solution across the veins, which is particularly problematic as symplastic pathways exist between vasculature and mesophyll cells [45]. As such, the contrast solution traverses through the cell rather than around them in an apoplastic manner. Extending the incubation time merely allows more time for the solution to diffuse through the cells, rather than bypassing them. Although vacuum impregnation of leaflets were attempted (data not shown), a different set of problems were encountered. The contrast agent is in essence a $10 \%$ metallic salt solution, which inherently has the ability to dehydrate, distort and damage the sample. This is typically not an issue with 3D samples, as the outer layer effectively acts as a buffer zone for damage. Leaves however, being two dimensional, did not have this buffer zone and the detrimental effects were almost immediate and sample stability reduced to the point where movement artifacts were rampant. The lack of a sacrificial layer also resulted in unmitigated contrast solution migration, resulting in large patches of contrast flooded mesophyll cells with no contrast improvement. Therefore it is recommended that conventional optical clearing techniques with fluorescent microscopy should be utilized for highly planar samples such as leaves [46].

Second, timing is critical to the success of this contrast enhancement protocol. As the solution is dehydrating and potentially damaging to the sample, an upper limit is inherently present for the duration of incubation. Although the timeframe is typically well beyond what is required for successful imaging. Additionally, protocol timing is reliant on the diffusivity characteristics of the sample. Indeed, Fick's law stipulates the rate of diffusion is dependent on the path length as well as diffusivity of the encountered path. Large tomato cells grant a shorter path to the center, while small pear cells inevitably prolongs the distance to the specimen center. Furthermore, different samples likely differ in diffusivity in the apoplastic path to the center, which is dependent on composition and physical characteristics of the cell boundaries. In any case, detailed characterization of cell wall composition is well beyond the scope of this study. Thus it is much quicker for the experimenter to run a time series trial to experimentally determine the necessary incubation period for achieving necessary contrast enhancement.

\section{Concluding remarks}

In this paper, cesium iodide is presented as a viable contrast enhancing agent for improving the accuracy of segmented data derived from X-ray micro-CT scans. The benefits of utilizing such a solution are demonstrated in this paper. Although the methodology is currently imperfect, sample type specific optimizations and validation along with more advanced segmentation algorithms in the future can be anticipated to minimize the shortcomings of this contrast solution. This method should prove valuable to the plant science field.

\section{Authors' contributions \\ ZW was involved in the design, data acquisition, analysis and the writing of this manuscript. PV and BN was involved in the design, analysis, interpreta- tion and revisions to the manuscript. All authors read and approved the final manuscript. \\ Author details \\ 1 Division MeBioS, Department of Biosystems, KU Leuven - University of Leuven, Willem de Croylaan 42, 3001 Leuven, Belgium. ${ }^{2}$ Flanders Centre of Postharvest Technology, Willem de Croylaan 42, 3001 Leuven, Belgium.}

\section{Acknowledgements}

The authors of this article greatly appreciates the financial support of the KU Leuven (C1 project C16/16/002), the Hercules Foundation (Project AKUL001(HER/09/016)), and VLAIO (ICON project iXCON, VIS traject i-FAST).

\section{Competing interests}

The authors declare that they have no competing interests.

\section{Availability of data and materials}

The full datasets generated and used by the current study are available from the corresponding author upon reasonable request.

\section{Consent for publication}

Not applicable.

\section{Ethics approval and consent to participate}

Not applicable.

\section{Funding}

Financial support was provided by the KU Leuven (C1 project C16/16/002), the Hercules foundation (project AKUL001(HER/09/016)), and VLAIO (ICON project iXCON, VIS traject i-FAST).

\section{Publisher's Note}

Springer Nature remains neutral with regard to jurisdictional claims in published maps and institutional affiliations.

Received: 6 October 2017 Accepted: 21 November 2017 Published online: 28 November 2017

References

1. Matsushima U, GrafW, Zabler S, Manke I, Dawson M, Choinka G, et al. 3D-analysis of plant microstructures: advantages and limitations of synchrotron X-ray microtomography. Int Agrophys. 2013;27:23-30. 
2. Abera MK, Verboven P, Herremans E, Defraeye T, Fanta SW, Ho QT, et al. 3D virtual pome fruit tissue generation based on cell growth modeling. Food Bioprocess Technol. 2014;7(2):542-55.

3. Aregawi WA, Abera MK, Fanta SW, Verboven P, Nicolai B. Prediction of water loss and viscoelastic deformation of apple tissue using a multiscale model. J Phys: Condens Matter. 2014;26(46):464111.

4. Fanta SW, Abera MK, Aregawi WA, Ho QT, Verboven P, Carmeliet J, et al. Microscale modeling of coupled water transport and mechanical deformation of fruit tissue during dehydration. J Food Eng. 2014;124:86-96.

5. Herremans E, Verboven P, Verlinden BE, Cantre D, Abera M, Wevers M, et al. Automatic analysis of the 3-D microstructure of fruit parenchyma tissue using $X$-ray micro-CT explains differences in aeration. BMC Plant Biol. 2015;15(1):264.

6. Ho QT, Verboven P, Verlinden BE, Schenk A, Delele MA, Rolletschek H, et al. Genotype effects on internal gas gradients in apple fruit. J Exp Bot. 2010;61(10):2745-55.

7. Lammertyn J, Dresselaers T, Van Hecke P, Jancsók P, Wevers M, Nicolaï B. MRI and X-ray CT study of spatial distribution of core breakdown in "conference" pears. Magn Reson Imaging. 2003;21(7):805-15.

8. Léonard A, Blacher S, Nimmol C, Devahastin S. Effect of far-infrared radiation assisted drying on microstructure of banana slices: an illustrative use of X-ray microtomography in microstructural evaluation of a food product. J Food Eng. 2008;85(1):154-62.

9. Mendoza F, Verboven P, Ho QT, Kerckhofs G, Wevers M, Nicolaï B. Multifractal properties of pore-size distribution in apple tissue using X-ray imaging. J Food Eng. 2010;99(2):206-15.

10. Schoeman L, Williams P, du Plessis A, Manley M. X-ray micro-computed tomography $(\mu \mathrm{CT})$ for non-destructive characterisation of food microstructure. Trends Food Sci Technol. 2016:47:10-24.

11. Beckmann EC. CT scanning the early days. Br J Radiol. 2006;79:5-8.

12. Ritman EL. Current status of developments and applications of micro-CT. Annu Rev Biomed Eng. 2011;13(1):531-52.

13. Rousseau D, Widiez T, Di Tommaso S, Rositi H, Adrien J, Maire E, et al. Fast virtual histology using $X$-ray in-line phase tomography: application to the 3D anatomy of maize developing seeds. Plant Methods. 2015;11(1):55.

14. Lauridsen T, Glavina K, Colmer TD, Winkel A, Irvine S, Lefmann K, et al. Visualisation by high resolution synchrotron $\mathrm{X}$-ray phase contrast microtomography of gas films on submerged superhydrophobic leaves. Struct Biol. 2014;188(1):61-70.

15. Verboven $\mathrm{P}$, Herremans $\mathrm{E}$, Helfen $\mathrm{L}, \mathrm{Ho}$ QT, Abera M, Baumbach T, et al. Synchrotron X-ray computed laminography of the three-dimensional anatomy of tomato leaves. Plant J. 2015;81(1):169-82.

16. Lusic H, Grinstaff MW. X-ray-computed tomography contrast agents. Chem Rev. 2013;113(3):1641-66.

17. Carroll QB. Practical radiographic imaging. 8th ed. Springfield: Charles C Thomas Publisher; 2007

18. Andreucci M, Solomon R, Tasanarong A. Side effects of radiographic contrast media: pathogenesis, risk factors, and prevention. Biomed Res Int. 2014;2014:741018.

19. Widmark JM. Imaging-related medications: a class overview. Proc (Bayl Univ Med Cent). 2007;20(4):408-17.

20. Blonder B, De Carlo F, Moore J, Rivers M, Enquist BJ. X-ray imaging of leaf venation networks. New Phytol. 2012;196(4):1274-82.

21. Staedler YM, Masson D, Schönenberger J. Plant tissues in 3D via X-ray tomography: simple contrasting methods allow high resolution imaging. PLOS ONE. 2013;8(9):e75295.

22. Dhondt S, Vanhaeren H, Van Loo D, Cnudde V, Inzé D. Plant structure visualization by high-resolution X-ray computed tomography. Trends Plant Sci. 2010;15(8):419-22.

23. Thakur BR, Singh RK, Handa AK, Rao MA. Chemistry and uses of pectin-a review. Crit Rev Food Sci Nutr. 1997;37(1):47-73.

24. Dymek K, Panarese V, Herremans E, Cantre D, Schoo R, Toraño JS, et al. Investigation of the metabolic consequences of impregnating spinach leaves with trehalose and applying a pulsed electric field. Bioelectrochemistry. 2016;112:153-7.

25. Panarese V, Herremans E, Cantre D, Demir E, Vicente A, Gómez Galindo F, et al. X-ray microtomography provides new insights into vacuum impregnation of spinach leaves. J Food Eng. 2016:188:50-7.

26. Mendoza F, Verboven P, Mebatsion HK, Kerckhofs G, Wevers M, Nicolaï B. Three-dimensional pore space quantification of apple tissue using X-ray computed microtomography. Planta. 2007;226(3):559-70.
27. Verboven P, Kerckhofs G, Mebatsion HK, Ho QT, Temst K, Wevers M, et al. Three-dimensional gas exchange pathways in pome fruit characterized by synchrotron X-ray computed tomography. Plant Physiol. 2008;147(2):518-27.

28. Vincent JFV. Relationship between density and stiffness of apple flesh. J Sci Food Agric. 1989;47(4):443-62.

29. Musse M, De Guio F, Quellec S, Cambert M, Challois S, Davenel A. Quantification of microporosity in fruit by MRI at various magnetic fields: comparison with X-ray microtomography. Magn Reson Imaging. 2010;28(10):1525-34

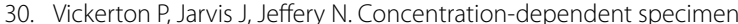
shrinkage in iodine-enhanced microCT. J Anat. 2013;223(2):185-93.

31. Buytaert J, Goyens J, De Greef D, Aerts P, Dirckx J. Volume shrinkage of bone, brain and muscle tissue in sample preparation for micro-CT and light sheet fluorescence microscopy (LSFM). Microsc Microanal. 2014:20(4):1208-17.

32. Roerdink J, Meijster A. The watershed transform: definitions, algorithms and parallelization strategies. Fundam Inform. 2000:41(1-2):187-228.

33. Barrett DM, Garcia E, Wayne JE. Textural modification of processing tomatoes. Crit Rev Food Sci Nutr. 1998;38(3):173-258.

34. De Belie N, Hallett IC, Harker FR, De Baerdemaeker J. Influence of ripening and turgor on the tensile properties of pears: a microscopic study of cellular and tissue changes. J Am Soc Hortic Sci. 2000;125(3):350-6.

35. Cheniclet C, Rong WY, Causse M, Frangne N, Bolling L, Carde J-P, et al. Cell expansion and endoreduplication show a large genetic variability in pericarp and contribute strongly to tomato fruit growth. Plant Physiol. 2005:139(4):1984-94.

36. Czerednik A, Busscher M, Angenent GC, de Maagd RA. The cell size distribution of tomato fruit can be changed by overexpression of CDKA1. Plant Biotechnol J. 2015;13(2):259-68.

37. Devaux MF, Bouchet B, Legland D, Guillon F, Lahaye M. Macro-vision and grey level granulometry for quantification of tomato pericarp structure. Postharvest Biol Technol. 2008:47(2):199-209.

38. Legland D, Devaux M-F, Bouchet B, Guillon F, Lahaye M. Cartography of cell morphology in tomato pericarp at the fruit scale. J Microsc. 2012;247(1):78-93.

39. Pierik R, van Aken JM, Voesenek LACJ. Is elongation-induced leaf emergence beneficial for submerged Rumex species? Ann. Bot 2009;103(2):353-7.

40. Visser EJW, Bögemann GM. Measurement of porosity in very small samples of plant tissue. Plant Soil. 2003;253(1):81-90

41. Hajiboland R, Farhanghi F, Aliasgharpour M. Morphological and anatomical modifications in leaf, stem and roots of four plant species under boron deficiency conditions. An Biol. 2012;34:15-29.

42. Avivi Y, Lev-Yadun S, Morozova N, Libs L, Williams L, Zhao J, et al. Clausa, a tomato mutant with a wide range of phenotypic perturbations, displays a cell type-dependent expression of the homeobox gene LeT6/TKn2. Plant Physiol. 2000;124(2):541-52.

43. Pieruschka R, Schurr U, Jahnke S. Lateral gas diffusion inside leaves. J Exp Bot. 2005;56(413):857-64.

44. Pajor R, Fleming A, Osborne CP, Rolfe SA, Sturrock CJ, Mooney SJ. Seeing space: visualization and quantification of plant leaf structure using X-ray micro-computed tomography. J Exp Bot. 2013:64(2):385-90.

45. Lemoine R, La Camera S, Atanassova R, Dédaldéchamp F, Allario T, Pourtau N, et al. Source-to-sink transport of sugar and regulation by environmental factors. Front Plant Sci. 2013;4(July):272.

46. Warner CA, Biedrzycki ML, Jacobs SS, Wisser RJ, Caplan JL, Sherrier DJ. An optical clearing technique for plant tissues allowing deep imaging and compatible with fluorescence microscopy. Plant Physiol. 2014;166(4):1684-7. 